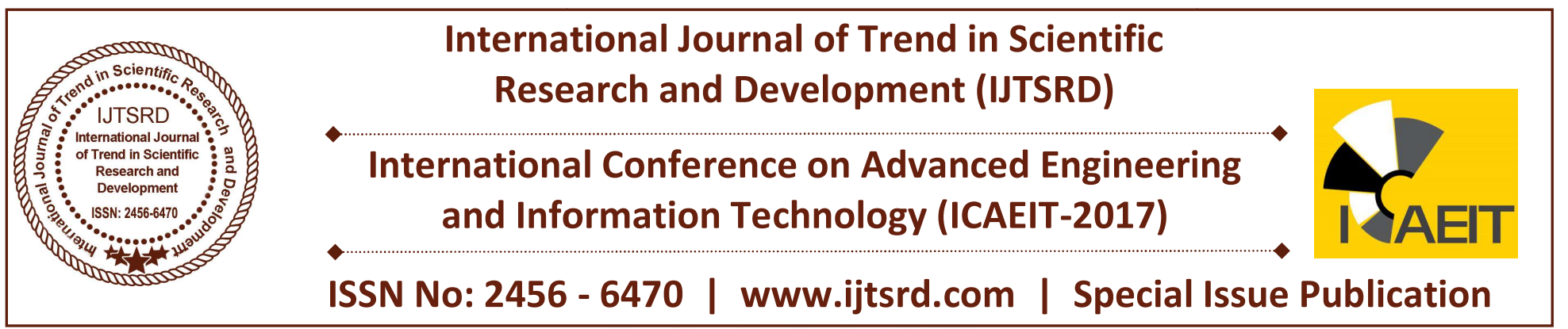

\title{
Performance Studies on Utilization of Ceramic Waste Tile and Quarry Dust as Partial Replacement of Gravel and Sand in Concrete
}

\author{
Nahushananda Chakravarthy, Mohammed Maina, Siti Hamidah Abdull Rahman \\ Linton University College, Mantin, Negeri Sembilan, Malaysia
}

\begin{abstract}
This paper present the experimental results obtained from the incorporation of ceramic waste tile (CWT) and quarry dust (QD) as a partial replacement to coarse and fine aggregate with different percentages in concrete. The concrete specimens were casted with ceramic waste tile as coarse aggregate replacing with natural coarse aggregate at $0 \%, 5 \%, 10 \%$, and $15 \%$, followed by quarry dust replacing with fine aggregate at $0 \%, 20 \%, 40 \%$, and $60 \%$ respectively. The experimental results at fresh state shows that the maximum slump is attained at $0 \%$ which is $50 \mathrm{~mm}$ and the compacting factor test result shows $0.92 \mathrm{~mm}$ at $0 \%$. A total 54 samples of Cubes, cylinders and beams were cast and tested for compressive strength, split tensile strength and flexural strength at 7,14 and 28 days of curing respectively. The results show that the percentage increase in CWT and QD will decrease in strength compared to the normal concrete. The experimental compressive strength, flexural strength and tensile strength concrete containing ceramic waste tile and quarry dust are presented in this paper.
\end{abstract}

Keywords: Ceramic waste tile, Quarry dust, compressive, flexural, splitting tensile.

\section{INTRODUCTION}

Concrete is a building material which is mixture of cement, water and aggregate. Concrete become an inevitable construction material in present day due ease of availability, economical and durable etc. The increase in consumption of concrete using common aggregate have reduced the amount of aggregates in nature and damage to the environment. Due to increased usage of natural aggregates, the incorporation of waste material will give suitable solution in preparing concrete.

Based on previous research, ceramic waste can be transformed into useful coarse aggregate and quarry dust as fine aggregate. The properties of ceramic waste coarse aggregate are within the range of the values of concrete-making aggregate and they are not significantly different from those of conventional concrete [1]. M. Veera Reddy used ceramic scrap as coarse aggregate replacement in concrete, the ceramic scrap incorporation more than $20 \%$ leads to reduction of strength compared to conventional mix [2]. I. B. Topcu and M. Canbaz, used crushed tile aggregate (CTA) as coarse aggregate in concrete. The unit weight of CTA concrete has decreased $4 \%$ according to experimental results. The use of CTA caused a 40 $\%$ loss in compressive and splitting tensile strengths. CTA also negatively affected abrasion and freezethaw durability. According to these results, $100 \%$ replacement of CTA as a coarse aggregate is not appropriate. The use of CTA in concrete has positive effects on the environment and obtaining lower costs. [3]. D. Tavakoli et al., used waste ceramic tile as aggregate in concrete. The Use of ceramic wastage in concrete production causes no remarkable effect in the properties of concrete. In these measures, not only an increase in compressive strength, but also a decrease in unit weight and lack of remarkable negative effect on water absorption is reported [4].

However, the research were conducted on replacement of CWT to coarse aggregate replacement but, this research work carried out on replacement of 
CWT to coarse aggregate and replacement of quarry dust to fine aggregate.

\section{Materials}

\subsection{Cement}

The term cement refers to a powdery material that binds. Cement act as a binding agent. In this research work ordinary Portland cement was used. This type of cement is generally used for all construction purpose.

\subsection{Coarse aggregate}

The selection of appropriate type of coarse aggregate has a direct influence on the strength of concrete. Coarse aggregate constitutes gravel or crush stone. Gravel of maximum size $20 \mathrm{~mm}$ was used in this research.

\subsection{Fine aggregate}

The fine aggregate was dried under steady room temperature for about two days to acquire a dry and appropriate condition for mixing. River sand was used as fine aggregate in this research. The grading of the fine aggregate was observed to prevent the likely block of the voids and appropriate penetration of the mortar.

\subsection{Water}

Water is used for the hydration of cement in order to bind with aggregates. The normal tap water available in the laboratory used in this research. The water was clean and free from any other impurities.

\subsection{Ceramic waste tile}

The ceramic waste tile used in this research work was obtained from oriental ceramic tile industry at seremban, Malaysia. The preparation of the ceramic waste tile involves the breakage of the tiles into small pieces of about $5 \mathrm{~mm}-40 \mathrm{~mm}$ sizes by a hammer. These small pieces are then fed into vibrator and sieved to get the required coarse aggregate size.

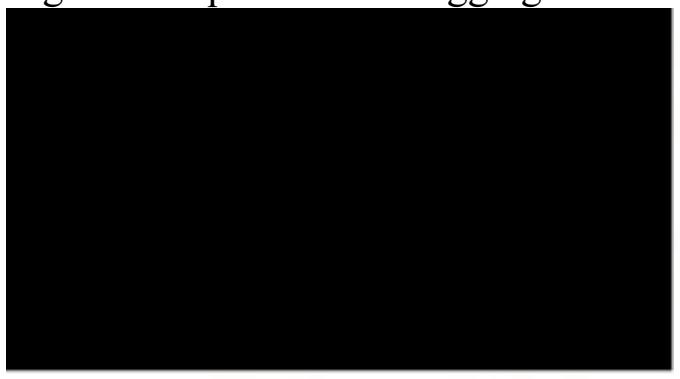

Figure1. Ceramic waste tile

\section{6 quarry dust}

The quarry dust for this research work was collected from a quarry near betang benar, Malaysia. The quarry dust was sieved until the ideal fine aggregate size was achieved. The sizes of the quarry dust is between $2.36 \mathrm{~mm}$ to $150 \mu \mathrm{m}$.

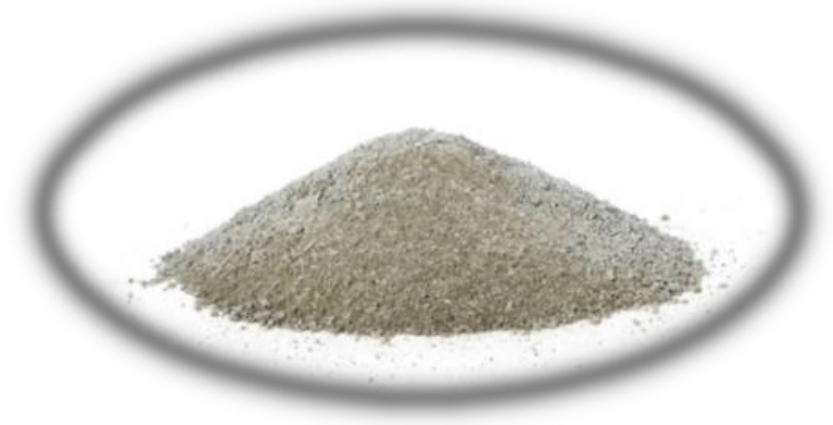

Figure1. Quarry dust

\section{Mix proportions}

The mix proportion for the concrete used for compressive strength, flexural strength and split tensile strength are as shown in Table 1, Table 2 and Table 3.

Table 1: Mix proportion for a cube compressive strength

\begin{tabular}{|c|c|c|c|c|c|c|}
\hline Materials (\%) & Water content & Cement content & \multicolumn{2}{|c|}{ Fine aggregate } & \multicolumn{2}{c|}{ Coarse aggregate } \\
\hline $\begin{array}{c}5 \% \mathrm{CWT} \\
20 \% \mathrm{QD}\end{array}$ & 0.74 & 1.48 & 0.591 & 2.362 & 0.221 & 4.207 \\
\hline $\begin{array}{c}10 \% \mathrm{CWT} \\
40 \% \mathrm{QD}\end{array}$ & 0.74 & 1.48 & 1.181 & 1.771 & 0.443 & 3.985 \\
\hline $\begin{array}{c}15 \% \mathrm{CWT} \\
60 \% \mathrm{QD}\end{array}$ & 0.74 & 1.48 & 1.771 & 1.181 & 0.664 & 3.764 \\
\hline
\end{tabular}

\section{Results and discussions}

In this study performance of CWT and QD incorporated concrete were observed in fresh and hardened state. The performance of fresh concrete measured using slump and compaction factor test and hardened concrete measured using compressive, flexural and spilt tensile strength tests. 


\subsection{Slump test}

Fresh concrete must be workable only when it easily placed, compacted, transported and casted easily without segregation. In this study concrete was tested for workability before the concrete placing into the moulds. The mix combination of all replacement materials at different percentage of CWT $5 \%, 10 \%$, $15 \%$ and $\mathrm{QD} 20 \%, 40 \%, 60 \%$ were used. The results of the slump test are as shown in Table 4.

Table 4: Slump test

\begin{tabular}{|c|c|c|c|}
\hline \multirow{2}{*}{$\begin{array}{c}\text { Batch } \\
\text { No }\end{array}$} & \multicolumn{2}{|c|}{ Replacement of materials (\%) } & $\begin{array}{c}\text { Slump } \\
\text { CWT (\%) }\end{array}$ \\
\hline 1 & $0 \%$ & $0 \%$ & 50 \\
\hline 2 & $5 \%$ & $20 \%$ & 46 \\
\hline 3 & $5 \%$ & $40 \%$ & 43 \\
\hline 4 & $5 \%$ & $60 \%$ & 42 \\
\hline 5 & $10 \%$ & $20 \%$ & 41 \\
\hline 6 & $10 \%$ & $40 \%$ & 39 \\
\hline 7 & $10 \%$ & $60 \%$ & 36 \\
\hline 8 & $15 \%$ & $20 \%$ & 32 \\
\hline 9 & $15 \%$ & $40 \%$ & 31 \\
\hline 10 & $15 \%$ & $60 \%$ & 30 \\
\hline
\end{tabular}

In Table 4, the results of slump test with the replacement materials 5\% CWT, 20\% QD, $10 \% \mathrm{CWT}, 40 \%$ QD and $15 \%$ CWT, $60 \%$ QD are shown. The result of the slump test specifies that the highest slump was obtained at the control sample mix with $0 \%$ CWT and $0 \%$ QD which was $50 \mathrm{~mm}$. Hence, increase in percentage of CWT and QD will not be a good workable concrete.

Table2: Mix proportion for a flexural test specimen

\begin{tabular}{|c|c|c|c|c|c|c|}
\hline Materials (\%) & Water content & Cement content & \multicolumn{2}{|c|}{ Fine aggregate } & \multicolumn{2}{c|}{ Coarse aggregate } \\
\hline $\begin{array}{c}5 \% \mathrm{CWT} \\
20 \% \mathrm{QD}\end{array}$ & 1.11 & 2.22 & 0.886 & 3.542 & 0.332 & 6.31 \\
\hline $\begin{array}{c}10 \% \mathrm{CWT} \\
40 \% \mathrm{QD}\end{array}$ & 1.11 & 2.22 & 1.771 & 2.657 & 0.664 & 5.978 \\
\hline $\begin{array}{c}15 \% \mathrm{CWT} \\
60 \% \mathrm{QD}\end{array}$ & 1.11 & 2.22 & 2.657 & 1.771 & 0.996 & 5.646 \\
\hline
\end{tabular}

Table3: Mix proportion for a split tensile test

\begin{tabular}{|c|c|c|c|c|c|c|}
\hline Materials (\%) & Water content & Cement content & \multicolumn{2}{|c|}{ Fine aggregate } & \multicolumn{2}{|c|}{ Coarse aggregate } \\
\hline $\begin{array}{c}5 \% \mathrm{CWT} \\
20 \% \mathrm{QD}\end{array}$ & 0.407 & 0.814 & 0.325 & 1.299 & 0.122 & 2.313 \\
\hline $\begin{array}{c}10 \% \mathrm{CWT} \\
40 \% \mathrm{QD}\end{array}$ & 0.407 & 0.814 & 0.65 & 0.974 & 0.244 & 2.192 \\
\hline $\begin{array}{c}15 \% \mathrm{CWT} \\
60 \% \mathrm{QD}\end{array}$ & 0.407 & 0.814 & 0.974 & 0.65 & 0.365 & 2.070 \\
\hline
\end{tabular}

\subsection{Compaction factor test}

The mix proportions of replacement materials at different percentage of CWT $5 \%, 10 \%, 15 \%$ and QD 20\%, 40\%, 60\% were used in compaction factor test. The results of the compaction factor test are as shown in Table 5. 
Table 5: Compaction factor test

\begin{tabular}{|c|c|c|c|}
\hline \multirow{2}{*}{$\begin{array}{c}\text { Batch } \\
\text { No }\end{array}$} & \multicolumn{2}{|c|}{ Replacement of materials (\%) } & C.F \\
\cline { 2 - 3 }$(\mathrm{mm})$ \\
\hline 1 & $0 \%$ & $0 \%$ & 0.92 \\
\hline 2 & $5 \%$ & $20 \%$ & 0.89 \\
\hline 3 & $5 \%$ & $40 \%$ & 0.87 \\
\hline 4 & $5 \%$ & $60 \%$ & 0.86 \\
\hline 5 & $10 \%$ & $20 \%$ & 0.83 \\
\hline 6 & $10 \%$ & $40 \%$ & 0.8 \\
\hline 7 & $10 \%$ & $60 \%$ & 0.78 \\
\hline 8 & $15 \%$ & $20 \%$ & 0.77 \\
\hline 9 & $15 \%$ & $40 \%$ & 0.75 \\
\hline 10 & $15 \%$ & $60 \%$ & 0.72 \\
\hline
\end{tabular}

It was observed that combination of CWT to QD concrete caused some changes in the compacting factor results. From Table 5, it is noticed that the replacement of sand with QD at different percentages reduces the workability. By merely examining the results of the test, the compacting factor decrease with an increase in percentage of both Ceramic waste tile (CWT) and quarry dust (QD). It was also observed that the control mix has the higher compacting factor while the mixture $15 \% \mathrm{CWT}$ and $60 \%$ QD has the lowest compacting value of 0.72 .

\subsection{Compressive strength test}

Compressive strength is the first aspect of consideration when testing mechanical properties of concrete. The specimens were tested for three selected curing periods of $7,14,28$ days with 5\%, $10 \%$ and $15 \%$ replacement to coarse aggregate using ceramic waste tile and $20 \%, 40 \%$ and $60 \%$ replacement to fine aggregate by quarry dust. The Compressive strength test results are as shown in Table 6.

The results shows the absolute correlation in the increase and decrease of the compressive strength with respect to percentage replacements. From the Table 6 it is noted that higher compressive strength was attained at $0 \%$ at the age of 28 days with a higher compressive strength of $26.57 \mathrm{MPa}$.

Table 6: Compressive strength results

\begin{tabular}{|c|c|c|c|c|}
\hline \multicolumn{2}{|c|}{ Percentage replacement } & \multicolumn{3}{|c|}{ Compressive strength (Mpa) } \\
\hline CWT (\%) & QD (\%) & 7 days & 14 days & 28 days \\
\hline 0 & 0 & 19.71 & 20.64 & 26.57 \\
\hline 5 & 20 & 18.24 & 23.97 & 25.54 \\
\hline 10 & 40 & 17.97 & 23.24 & 24.26 \\
\hline 15 & 60 & 16.64 & 18.64 & 24.10 \\
\hline 5 & 60 & 17.76 & 18.76 & 24.19 \\
\hline 15 & 20 & 18.12 & 18.12 & 25.10 \\
\hline
\end{tabular}

\subsection{Flexural strength test}

Flexural strength tests investigate the capacity of the concrete beam to resist failure due to bending. Here, beam sample of numerous partial replacement levels and curing days were subjected to an external load were the corresponding maximum load were noted. The results are as shown in Table 7.
The results shows the correlation in the increase and decrease of the flexural strength with respect to percentage replacements. Hence it is obvious that the curing days does not affect 15\% CWT, 60\% QD replacement where the 28 curing days attain more strength than that of the 14 curing days. The flexural strength test specimens are as shown in Figure 1 and Figure 2 . 
Table 7: Flexural strength test results

\begin{tabular}{|c|c|c|c|c|}
\hline \multicolumn{3}{|c|}{ Percentage replacement } & \multicolumn{3}{|c|}{ Flexural strength (Mpa) } \\
\hline CWT (\%) & QD (\%) & 7 days & 14 days & 28 days \\
\hline 0 & 0 & 4.95 & 5.57 & 5.84 \\
\hline 5 & 20 & 4.72 & 4.85 & 5.56 \\
\hline 10 & 40 & 3.97 & 4.60 & 4.95 \\
\hline 15 & 60 & 3.88 & 3.27 & 4.02 \\
\hline 5 & 60 & 4.09 & 4.25 & 4.97 \\
\hline 15 & 20 & 3.96 & 4.00 & 4.27 \\
\hline
\end{tabular}

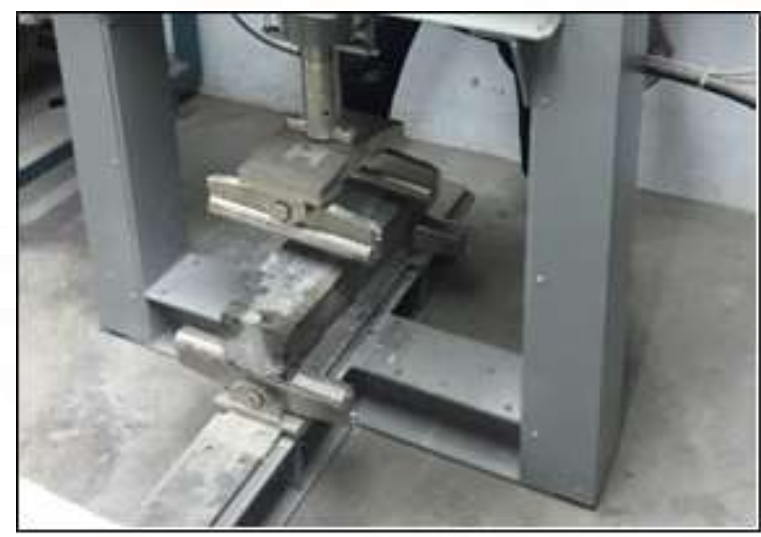

Figure1. Flexural strength specimen before applying load

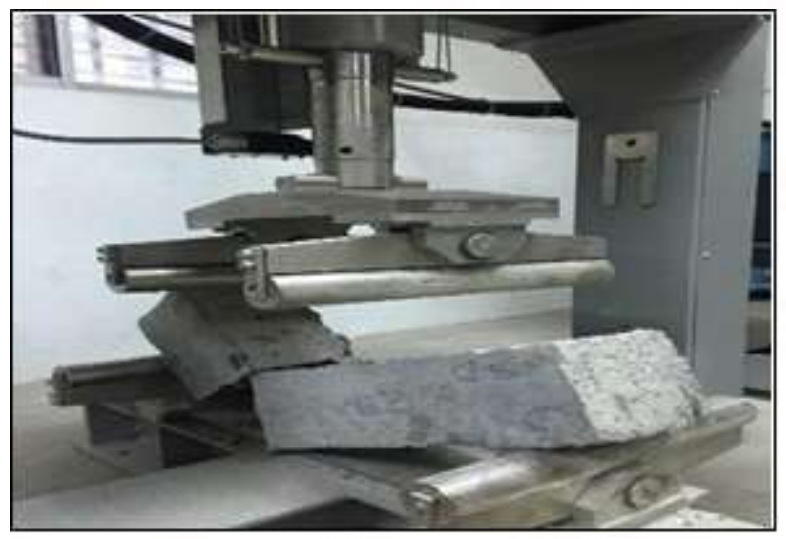

Figure2. Flexural strength specimen after applying load

\subsection{Split tensile strength}

This split tensile test involves the applying of compressive line loads along the opposite generators of a concrete cylinder which results in a uniform tensile stress to be induced over a nearly two-third of the loaded diameter causing the concrete cylinder to fail by splitting. The test results are as shown in Table 8 .

The splitting tensile strength results of concrete with coarse and fine aggregate material are partially substituted by ceramic waste tile and quarry dust at 7, 14 and 28 curing days. However, curing day shows impact on the increase of the tensile strength values, it is clearly seen that when coarse and fine aggregates are replaced both by ceramic waste tile and quarry dust at the optimum replacement level (10\% CWT and $40 \%$ QD), a reduced value of the split tensile strength is achieved. This indicates that as the percentage of the CWT and QD increases the tensile strength decreases. The split tensile test set up as shown in Figure 3 and Figure 4.

Table 8: Flexural strength test results

\begin{tabular}{|c|c|c|c|c|}
\hline \multicolumn{2}{|c|}{$\begin{array}{c}\text { Percentage } \\
\text { replacement }\end{array}$} & \multicolumn{3}{c|}{$\begin{array}{c}\text { Split tensile strength } \\
\text { (Mpa) }\end{array}$} \\
\hline CWT (\%) & QD (\%) & 7 days & 14 days & 28 days \\
\hline 0 & 0 & 2.85 & 3.65 & 4.20 \\
\hline 5 & 20 & 2.55 & 3.10 & 3.55 \\
\hline 10 & 40 & 2.35 & 2.70 & 3.10 \\
\hline 15 & 60 & 2.10 & 2.25 & 2.30 \\
\hline 5 & 60 & 2.50 & 3.05 & 3.40 \\
\hline 15 & 20 & 2.20 & 2.30 & 2.60 \\
\hline
\end{tabular}

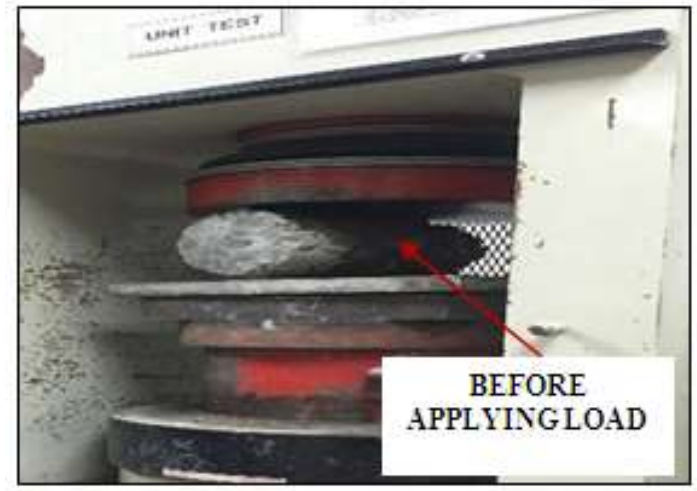

Figure3. Split tensile test set up

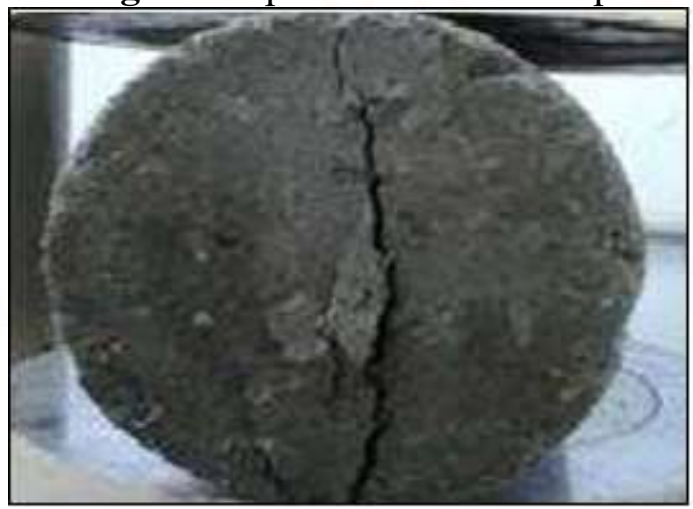

Figure4. Split tensile failure specimen 


\section{Conclusions}

The use of CWT and QD are good alternative for the replacement of conventional aggregates. The use of these materials not only help to overcome the dependence on the natural aggregates or reduction on the cost of production but also can be a good alternative for waste material utilization which promote eco-system balance. From the research conducted, the conclusions are made as follows:

$>$ The study indicated that an increase in the percentage of CWT and QD in the mixture decreases the workability.

$>$ The $5 \%$ CWT and $20 \%$ QD is found to be the optimum replacement compared to all mixtures.

$>$ The results show the CWT and QD content increased, the compressive strength, flexural strength and splitting tensile strength of the concrete decreased.

$>$ This could be concluded that quarry dust and ceramic waste tile are suitable substitute for conventional aggregates in concrete production.

\section{References}

1. Al Bakri, Mohd Mustafa, H. Kamarudin, Shamsul Baharin Che Mohd Ruzaidi, R. Rozaimah, and Nur Khairiatun Nisa. "Concrete with ceramic waste and quarry dust aggregates." In 5th Annual Conference Management in Construction Researchers Association, pp. 383388. 2006.

2. Reddy, Veera M. "Investigations on stone dust and ceramic scrap as aggregate replacement in concrete." International journal of civil and structural engineering 1, no. 3 (2010): 661.

3. Topcu, I. B., and M. Canbaz. "Utilization of crushed tile as aggregate in concrete." Iranian Journal of Science and Technology 31, no. B5 (2007): 561.

4. Tavakolia, D., A. Heidari, and M. Karimian. "Properties of concretes produced with waste ceramic tile aggregate." Asian Journal of Civil Engineering 14, no. 3 (2013): 369-382.

5. Alnuaimi, A. S. "Effects of copper slag as a replacement for fine aggregate on the behavior and ultimate strength of reinforced concrete slender columns." The Journal of Engineering Research [TJER] 9, no. 2 (2012): 90-102.

6. Standard, British. "Part-102 (1983) Testing Concrete Method for Determination of Slump, London." British Standard Institution (1881).
7. Shetty, M. S. "Concrete technology." S. chand \& company LTD(2005): 420-453.

8. Neville, Adam M. Properties of concrete. Vol. 4. London: Longman, 1995.

9. Raval, Amitkumar D., Indrajit N. Patel, and Jayeshkumar Pitroda. "Re-use of ceramic industry wastes for the elaboration of eco-efficient concrete." International Journal of Advanced Engineering Reseach and Studies 2, no. 3 (2013): 103-5.

10. Al Bakri, A. Mohd Mustafa, M. N. Norazian, H. Kamarudin, and G. Che Mohd Ruzaidi. "The Potential Of Recycled Ceramic Waste As Coarse Aggregates For Concrete." In Malaysian Universities Conferences on Engineering and Technology, pp. 1-3. 2008.

11. Murali, G., and V. R. Ramkumar. "PROPERTIES OF CONCRETE WITH PARTIAL REPLACEMENT OF COARSE AGGREGATE." (2012).

12. Osei, Daniel Yaw. "Compressive Strength of Concrete Using Recycled Concrete Aggregate as Complete Replacement of Natural Aggregate." Journal of Engineering, Computers \& Applied Sciences (JEC\&AS) 2, no. 10 (2013): 26-30.

13. Medina, C., MI Sánchez De Rojas, and M. Frías. "Reuse of sanitary ceramic wastes as coarse aggregate in eco-efficient concretes." cement and concrete composites 34, no. 1 (2012): 48-54.

14. Lohani, T. K. "Optimum utilization of Quarry dust as partial replacement of sand in concrete." International Journal of Applied Science and Engineering Research (2012).

15. Al Bakri, A. M., M. N. Norazian, H. Kamarudin, M. A. A. Mohd Salleh, and A. Alida. "Strength of concrete based cement using recycle ceramic waste as aggregate." In Advanced Materials Research, vol. 740, pp. 734-738. Trans Tech Publications, 2013.

16. Norazian, Mohamed Noor, Hussin Kamarudin, and Mohd Salleh Mohd Arif Anuar. "Strength of concrete based cement using recycle ceramic waste as aggregate." (2013). 